\title{
The Critical Care Society of Southern Africa Consensus Guideline on ICU triage and rationing (ConICTri)
}

\author{
G M Joynt, ${ }^{1} \mathrm{MB}$ BCh; P D Gopalan, ${ }^{2} \mathrm{MB}$ ChB; A Argent, ${ }^{3} \mathrm{MB}$ BCh, MD; S Chetty, ${ }^{4} \mathrm{MB}$ ChB, PhD; R Wise, ${ }^{5} \mathrm{MB}$ ChB; V K W Lai, ${ }^{1} \mathrm{PhD}$; \\ E Hodgson, ${ }^{6} \mathrm{MB}$ BCh; A Lee, ${ }^{1} \mathrm{PhD}$; I Joubert, ${ }^{7} \mathrm{FCA}(\mathrm{SA})$; S Mokgokong, ${ }^{8} \mathrm{MB}$ BCh; S Tshukutsoane, ${ }^{9} \mathrm{BCur}$; G A Richards, ${ }^{10} \mathrm{MB} \mathrm{BCh}, \mathrm{PhD}$; \\ C Menezes, ${ }^{9,11} \mathrm{MD}$, PhD; L R Mathivha ${ }^{10} \mathrm{MB}$ ChB; B Espen, ${ }^{12}$ CCRN; B Levy, ${ }^{13} \mathrm{MB}$ ChB; K Asante, ${ }^{14} \mathrm{PhD} ;$ F Paruk, ${ }^{15} \mathrm{MB}$ ChB, PhD \\ ${ }^{1}$ Department of Anaesthesia and Intensive Care, The Chinese University of Hong Kong, Hong Kong \\ ${ }^{2}$ Department of Anaesthesiology and Critical Care, School of Clinical Medicine, University of KwaZulu-Natal, Durban, South Africa \\ ${ }^{3}$ Department of Paediatrics and Child Health, University of Cape Town, South Africa \\ ${ }^{4}$ Department of Anaesthesiology and Critical Care, Stellenbosch University, Cape Town, South Africa \\ ${ }^{5}$ Department of Anaesthesiology and Critical Care, School of Clinical Medicine, University of KwaZulu-Natal, Durban, and Edendale Hospital, \\ Pietermaritzburg, South Africa \\ ${ }^{6}$ Department of Anaesthesiology and Critical Care, School of Clinical Medicine, University of KwaZulu-Natal, Durban, and Inkosi Albert Luthuli \\ Central Hospital, Durban, South Africa \\ ${ }^{7}$ Department of Anaesthesia and Peri-operative Medicine, University of Cape Town and Groote Schuur Hospital, Cape Town, South Africa \\ ${ }^{8}$ Department of Neurosurgery, University of Pretoria, South Africa \\ ${ }^{9}$ Chris Hani Baragwanath Academic Hospital, Soweto, Johannesburg, South Africa \\ ${ }^{10}$ Department of Critical Care, Faculty of Health Sciences, University of the Witwatersrand, Johannesburg, South Africa \\ ${ }^{11}$ Department of Internal Medicine, Faculty of Health Sciences, University of the Witwatersrand, Johannesburg, South Africa \\ ${ }^{12}$ Centre for Health Professions Education, Stellenbosch University, Cape Town, South Africa \\ ${ }^{13}$ Netcare Rosebank Hospital, Johannesburg, South Africa \\ ${ }^{14}$ African Organization for Research and Training in Cancer, Cape Town, South Africa \\ ${ }^{15}$ Department of Critical Care, University of Pretoria, South Africa
}

Corresponding author: G M Joynt (gavinmjoynt@cuhk.edu.hk)

\begin{abstract}
Background. In South Africa (SA), administrators and intensive care practitioners are faced with the challenge of resource scarcity as well as an increasing demand for intensive care unit (ICU) services. ICU services are expensive, and practitioners in low- to middleincome countries experience the consequences of limited resources daily. Critically limited resources necessitate that rationing and triage (prioritisation) decisions are routinely necessary in SA, particularly in the publicly funded health sector.

Purpose. The purpose of this guideline is to utilise the relevant recommendations of the associated consensus meeting document and other internationally accepted principles to develop a guideline to inform frontline triage policy and ensure the best utilisation of adult intensive care in SA, while maintaining the fair distribution of available resources.

Recommendations. An overall conceptual framework for the triage process was developed. The components of the framework were developed on the basis that patients should be admitted preferentially when the likely incremental medical benefit derived from ICU admission justifies admission. An estimate of likely resource use should also form part of the triage decision, with those patients requiring relatively less resources to achieve substantial benefit receiving priority for admission. Thus, the triage system should maximise the benefits obtained from ICU resources available for the community. Where possible, practical examples of what the consensus group agreed would be considered appropriate practice under specified South African circumstances were provided, to assist clinicians with practical decisionmaking. It must be stressed that this guideline is not intended to be prescriptive for individual hospital or regional practice, and hospitals and regions are encouraged to develop specified local guidelines with locally relevant examples. The guideline should be reviewed and revised if appropriate within 5 years.

Conclusion. In recognition of the absolute need to limit patient access to ICU because of the lack of sufficient intensive care resources in public hospitals, this guideline has been developed to guide policy-making and assist frontline triage decision-making in SA. This document is not a complete plan for quality practice, but rather a template to support frontline clinicians, guide administrators and inform the public regarding appropriate triage decision-making.
\end{abstract}

S Afr Med J 2019;109(8):630-642. https://doi.org/10.7196.SAMJ.2019.v109i8b.13947 | S Afr J Crit Care 2019;35(1):53-65. https://doi.org/10.7196/SAJCC.2019.v35i1b.383

\section{Introduction}

The intensive care unit (ICU) provides a higher level of care than the general ward or intermediate care units, and is a place where patients with potential or established organ failure can receive 
close monitoring and life support treatment delivered by specially trained staff. ${ }^{[1]}$ In SA, ICUs generally provide a high standard of intensive care; however, because of the expensive nature of intensive care services, there are a limited number of ICU beds and facilities available. ${ }^{[2-5]}$ Rationing is therefore inevitable, and a priority system that is fair and efficient is required to ensure the ongoing provision of high-quality intensive care, with the best utilisation of available resources. Guidelines for making such ICU triage decisions are important to promote consistency, fairness and high standards of clinical decision-making at the bedside. ${ }^{[6-9]}$ Transparently promulgated and communicated guidelines also promote effective communication with patients, their surrogates, the public and referring doctors.

The purpose of this guideline is to utilise the relevant recommendations of the associated consensus meeting document, ${ }^{[10]}$ and other internationally accepted principles, to develop a guideline that informs frontline policy for patient triage, admission to and discharge from ICUs in SA. As stated in the Durban Declaration, all basic moral and ethical principles must be applied to ensure rational decision-making in intensive care, but particularly because intensive care is a limited resource, that the social justice principle as a competing interest must be recognised. ${ }^{[1]}$ The framework presented is designed to help maximise the use of ICU services to achieve the largest possible benefit for the most patients from available resources. This utilitarian ethical approach has been recommended by expert groups and ICU professional bodies internationally, ${ }^{[6,12-15]}$ and was recommended by the accompanying South African triage consensus statement. ${ }^{[10]}$

In addition, and to ensure fairness, further principles that should be met are briefly summarised (Table 1). The broad principles provided should serve to assist individual ICUs to develop their own local policy that best suits the specific requirements of the hospital. Individual ICUs are therefore encouraged to further define their scope of practice, service provision, and develop detailed guidelines for the implementation of triage, provided that the patient population is served according to the above principles.

\section{Methods}

The framework arises from a detailed discussion during the afternoon session of a full day, face-to-face round-table meeting at the Critical Care Society of Southern Africa (CCSSA) National Congress held at Sun City on 18 October 2017, and was informed by findings of the accompanying consensus statement, ${ }^{[10]}$ and previously described triage practices and available international consensus guidance. ${ }^{[6,15-20]}$ It thus serves as an application tool to assist the practical application of the principles agreed at the consensus meeting. ${ }^{[21]}$

After the round table meeting, a draft of the written guideline was circulated to the consensus group for comments and suggested modifications. After 2 formal rounds of consultation, the draft guideline was made openly available on the CCSSA website https:// www.criticalcare.org.za/ConICTri/Whatis from August 2018 for 3 months, and both invited participants and CCSSA members were asked to review and comment on the proposed draft. The site was open to public view during this period.

In response to suggestions received via the website portal, small additional changes were finalised during November 2018. Opinions received via the website were generally positively aligned with the content of the guideline. The guideline, with relevant open external consultation additions included, was circulated to all members of the consensus group in December 2018 for consensus and final approval.

\section{Consensus guideline}

The overall conceptual framework for the triage process is summarised in Fig. 1. The guideline text is divided into 7 parts to allow the components of the framework to be described in detail. Where possible, practical examples of what the consensus group agreed would be considered appropriate practice under qualified South African circumstances are provided to assist clinicians with practical decision-making. It must be stressed that this guideline is not intended to be prescriptive for individual hospital or regional practice, and hospitals and regions are encouraged to develop specified local guidelines with locally relevant examples.

\section{Table 1. Principles governing triage decisions*}

- Triage decisions should be made explicitly, transparently and documented clearly in the patient record.

- Triage decisions should be made without bias, and non-medical factors such as gender, race, religion, social status or educational attainment should not be considered when making triage decisions.

- Triage decisions should be based strictly on the patient's medical condition, and the likely incremental medical benefit to be derived from ICU admission (in comparison with the existing or alternative lower levels of care).

- Triage decisions should be supervised by a senior and experienced ICU doctor, and implemented according to individual unit policy.

- It is recommended that every ICU should have specific admission, discharge and triage guidelines, easily accessible by both hospital staff and the public.

- After careful assessment of a referred case, individual triage decisions should always be clearly communicated to the referring doctor/s, and the patient or their surrogates.

- In the presence of the current limited ICU resources available in SA, decisions to refuse ICU admission, in accordance with the principles defined in this document, may be made despite an anticipated undesirable outcome for that individual patient.

- A decision to decline admission may be made even though all ICU beds are not immediately occupied; however, it should reasonably be expected that the unoccupied bed would be required by a subsequent referred patient with a greater chance of incremental medical benefit. Thus, triage recommendations are applicable whether or not an immediate shortage is apparent because their continuous use will lead to more consistently equitable and efficient intensive care.

- A physician should also not be compelled by patients, their surrogates or others to provide treatment that is considered non-beneficial.

${ }^{*}$ Adapted and modified from Sprung $e$ t al. ${ }^{\left[{ }^{[6]}\right.}$ and the Guidelines for intensive care unit admission, discharge, and triage. ${ }^{[12}$ 


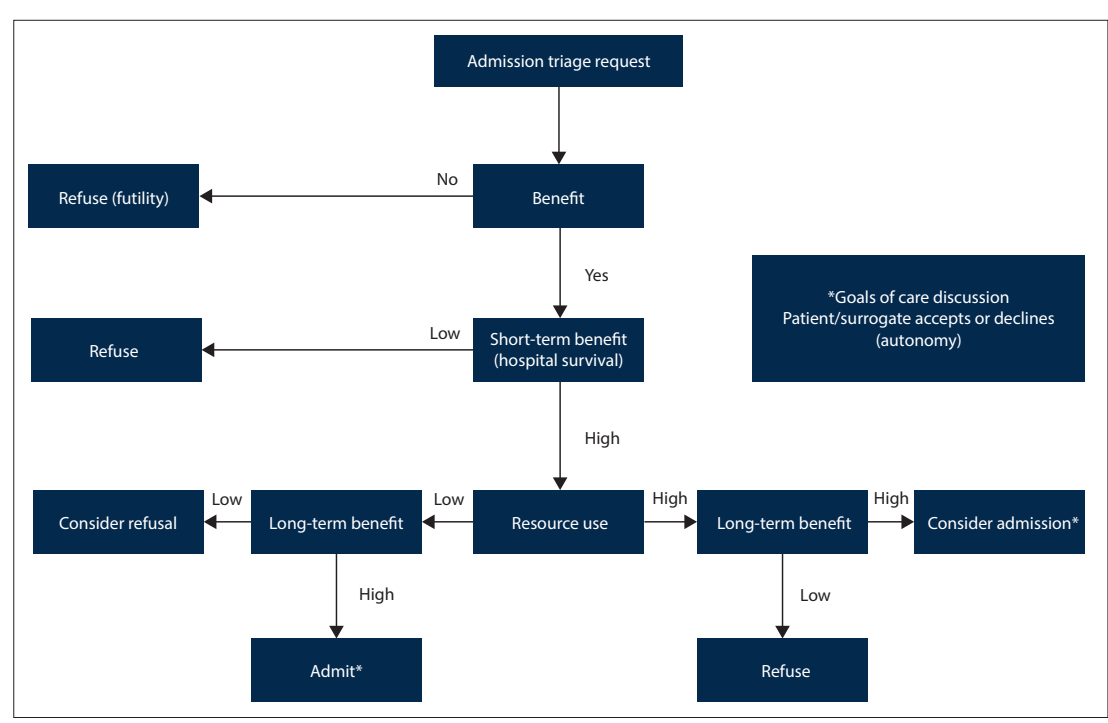

Fig. 1. A triage (prioritisation) decision is a complex clinical decision made when ICU beds are limited. A structured decision-making process is important to maximise transparency and improve consistency in decision-making. A clinical estimation of likely benefit (outcomes from ICU admission compared with outcomes expected if patient remained in the ward/other care area) is necessary, so that patients who will benefit most from ICU are given priority. Based on the expert group's experience, a hypothetical example of an acceptable triage threshold for an ICU that routinely performs triage at least on a daily basis, would approximate at least a 20 -30\% chance of survival for a severely ill patient at 3 - 6 months (threshold for long-term benefit). This assumes a 5\% chance of survival if the patient was left at their original level of care (usually a general ward). Some examples of conditions that the expert group believe would fail to meet these criteria are provided (Table 2). In addition, some examples of conditions that it would meet the criteria for non-beneficial care or futility (short and long term) are provided (Table 5).

This conceptual algorithm outlines a recommended process for making an individual triage decision. Each decision is made on the basis of an agreed triage threshold for the particular setting (e.g. stricter thresholds may be required during the winter surge, and academic units may require special arrangements to support elective surgery). Long-term benefit should include an assessment of expected quality of life, if considered appropriate (Table 3). As these examples are hypothetical, each unit should develop individual policies that take the above framework into account, but with clinical content and thresholds that are specified for local requirements. (Figure adapted from Joynt and Gomersall. ${ }^{[20]}$ )

${ }^{\star}$ Before the final decision to admit to ICU, and if admission is to be offered, patient preference regarding desire for admission should be explored with the patient or the patient's surrogate when appropriate.

\section{Triage priority for admission}

Patients categorised as high priority should be admitted to the ICU whenever possible (although in some units and regions of SA, the ICU resource shortage is so severe that not all high-priority cases can be admitted). If the ICU is fully occupied, attempts should be made to transfer these patients to other units within the region, if such a possibility exists.

High-priority patients fall into the following broad categories:

1. Critically ill patients with acute organ failure/s who require life support therapies that can only be provided in the ICU and are likely to derive substantial incremental benefit from ICU care compared with and may be refused ICU admission when resources (adequately staffed and equipped ICU beds) are limited. Thus, the available ICU resources are preserved for use by high-priority patients.

The threshold for determining the triage decision (magnitude of benefit required to be considered substantial) will be determined primarily by the balance of local ICU provision and demand for ICU services. For example, in a wellresourced hospital, with few referrals for ICU admission, only patients with a small chance of incremental benefit may be categorised as low priority and need be refused admission. Conversely, in a severely under-resourced hospital with many referrals for ICU admission, patients with a much greater chance of benefit may find themselves refused admission as the queue for admission will be filled with patients with a very high likelihood of benefit. Thus, the determination and description of the triage threshold ultimately is made by the ICU management, after broad consultation with senior ICU personnel and, where necessary, other stakeholders.

In the interests of fairness and consistency, triage thresholds in individual units should be defined and openly documented as clearly as possible by the ICU management, and respected by those performing triage, as well as referring medical teams. It is recognised that the availability of ICU beds throughout the country is highly variable, ${ }^{[3,4]}$ and consequently appropriate triage thresholds that are established for regions/clusters of units, or individual units, will vary, depending on the magnitude and consistency of pressure for beds. Triage thresholds may also vary from time to time, such as during a seasonal outbreak of respiratory or other infectious disease. ${ }^{[22,23]}$ Under circumstances where two or more patients of high priority both require admission, and all cannot be admitted because the ICU is fully occupied, the patient/s with the highest priority should be admitted first; or, should these patients be judged as having equally high priority, then on a first-come, first-served basis.

It should not be forgotten that patients with an extremely good prognosis may also not necessarily derive substantial benefit from ICU care, compared with a lower level of care, and may be refused admission on the 
basis of triage, for example a patient with chronic obstructive pulmonary disease (COPD) responding to non-invasive ventilation in a ward would derive little extra benefit from ICU admission. It would then be reasonable to reserve the ICU bed for a more ill patient (perhaps with a worse prognosis), but one likely to derive greater incremental benefit from admission.

\subsection{Decision-making process}

Upon referral of a patient for possible admission to an ICU with limited capacity for admission, the triage (prioritisation) process identifies a spectrum of patients who will likely derive substantial incremental benefit from ICU admission, and therefore should receive priority for admission. It is acknowledged that triage is a

\begin{tabular}{|c|c|}
\hline Severe trauma & - A TRISS with predicted mortality $>80 \%$ \\
\hline $\begin{array}{l}\text { Severe burns of patient with any two of } \\
\text { the following }\end{array}$ & $\begin{array}{l}\text { - Age }>60 \text { years } \\
\text { - }>40 \% \text { of total body surface area affected } \\
\text { - Severe inhalation injury }\end{array}$ \\
\hline Cardiac arrest & $\begin{array}{l}\text { - Unwitnessed cardiac arrest } \\
\text { - Witnessed cardiac arrest, not responsive to CPR within a reasonable period (e.g. } 30-45 \text { mins), } \\
\text { especially if presenting rhythm is non-shockable } \\
\text { - More than } 2 \text { episodes of cardiac arrest at presentation } \\
\text { - A second cardiac arrest }<72 \mathrm{~h} \text { following return of spontaneous circulation }\end{array}$ \\
\hline $\begin{array}{l}\text { Severe chronic disease and irreversible } \\
\text { organ failure }\end{array}$ & 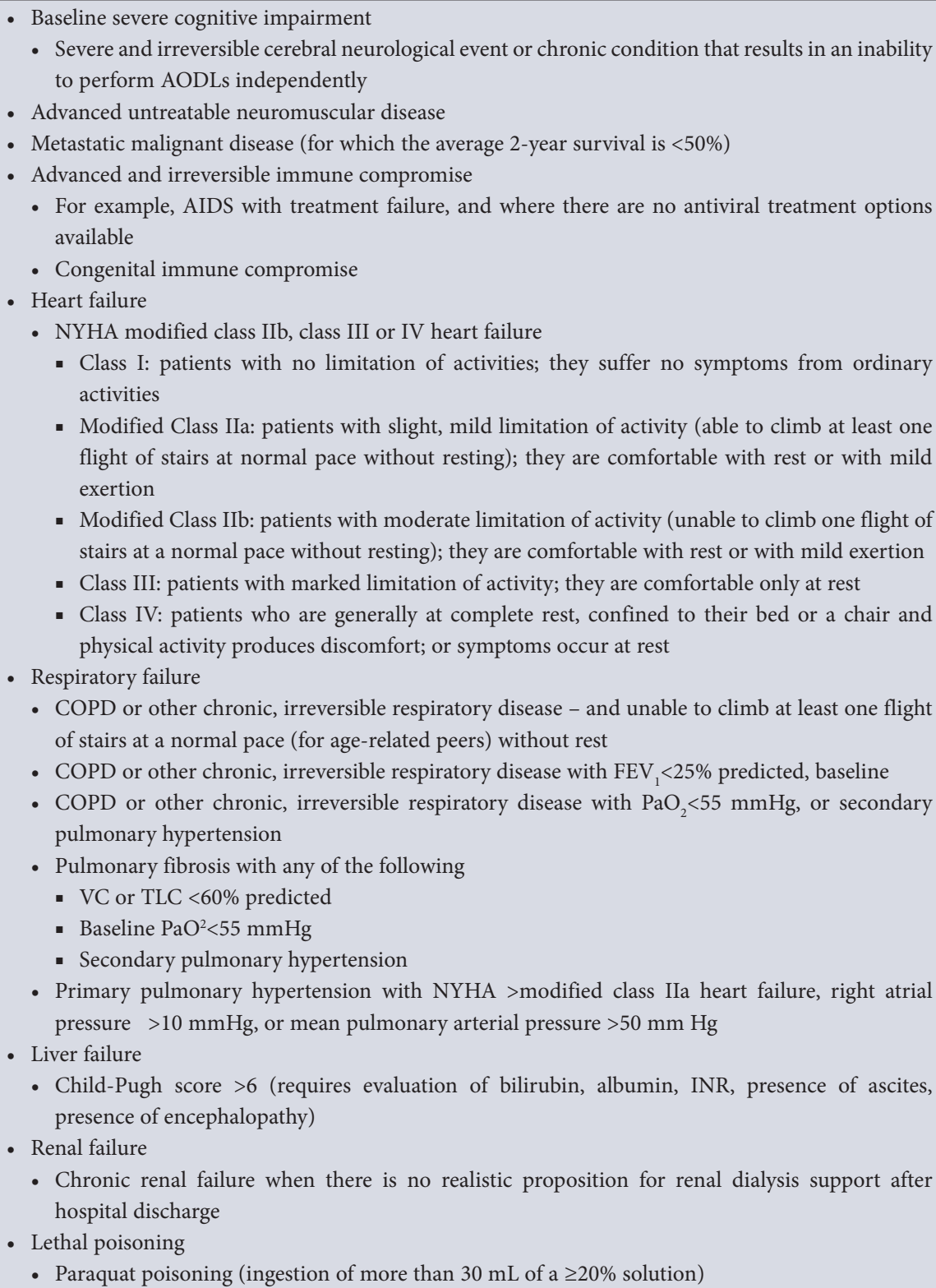 \\
\hline
\end{tabular}


complex clinical decision dependent on several factors. The use of scoring systems to objectively identify the triage threshold (sufficient incremental magnitude of mortality benefit likely to be derived from admission), while attractive, is not currently possible..$^{[24-26]}$ This question was discussed in more detail in the concurrent consensus statement. ${ }^{[10]}$ Simple, accessible and rapidly available point of care predictive scoring systems for mortality, when available, are recommended to assist prognostication and therefore the clinical estimate of magnitude of likely benefit. Unfortunately, few are suited to use in the triage setting. ${ }^{[27,28]}$ Thus, determining the triage threshold remains largely a considered clinical decision.

The algorithm in Fig. 1 describes how the clinical judgment of whether a patient meets the triage threshold should be framed, without prescribing the specific clinical requirements necessary to meet the triage threshold in individual units. To provide some practical guidance, an indicative example of criteria is provided in Tables 2, 3 and 5. Specific clinical requirements for individual units or groups of similar units, if deemed necessary, should be determined by local unit policy that will in turn be dependent on a local assessment of pressure for available beds. It is expected that these may be different from those provided in the examples that follow.

\subsection{Setting a triage threshold}

To assist individual units to develop and document processes and thresholds for triage decision-making based on local circumstances, some examples follow. Following the framework suggested in Fig. 1, the round-table participants constructed clinical descriptions or categories of patients that would not meet the triage threshold of 'substantial benefit' in a hypothetical unit with a daily requirement to refuse referred patients (Fig. 1, Tables 2, 3 and 5). In each of these clinical settings, the incremental difference in benefit from ICU admission would be expected to be small compared with that

Table 3. Examples of patient circumstances that could reasonably be classified as meeting conditions such that ICU admission may be considered undesirable based on quality of life ${ }^{*}$

End-stage dementia

Persistent vegetative or minimally conscious state

Cognitive impairment such that patients are dependent for all activities of daily living

${ }^{\star}$ These are illustrative examples only, and are neither prescriptive nor exhaustive of conditions and criteria that may be appropriate for triage.

\title{
Table 4. Administrative requirements for the effective implementation of recommendations
}

1. Nationally recommended framework for triage

2. Hospital triage committee, chaired by the Director of ICU, or nominated representative

3. Commitment of the senior hospital administration and meaningful involvement of all stakeholders to develop and implement formal, written, local triage policy and protocols

4. Formal and ongoing communication process between hospital triage committee and all stakeholders

5. Triage-capable ICU doctors (with appropriate knowledge and training)

6. Commitment to palliative care protocols for palliative care outside the ICU

7. Development of a data collection system to monitor triage decision-making and relevant outcomes

9. Conflict management process

\begin{abstract}
Table 5. Examples of patient circumstances that could reasonably be classified as meeting conditions such that ICU admission may be considered a 'non-beneficial' intervention in the South African context ${ }^{*}$

Patients facing imminent death - Failure to maintain sustained return of spontaneous circulation after resuscitation

- Metastatic cancer that has failed available therapy, or has limited therapeutic options

Neurological damage predicted to result in

- End-stage dementia

death or very severe disability

- Those declared brain dead who are not organ donors

- Persistent vegetative or minimally conscious state

Patients with underlying lethal conditions

- Patients with end-stage anuric chronic renal failure who are not eligible for long-term dialysis or renal replacement therapy

- Patients with end-stage chronic hepatic disease, now in fulminant failure, for whom transplantation is not an option

- Patients with established AIDS as result of HIV infection in an advanced state of disease. The World Health Organization defining criteria for AIDS should be used. ${ }^{\dagger}$

${ }^{\dagger}$ Patients should not be discriminated against purely on the basis of a known HIV-positive status. HIV-positive patients, whether on established antiretroviral therapy or not, where the reason for admission is not related to their underlying retroviral disease, may be considered as suitable candidates for admission, provided that they meet the established triage threshold as described in this document.
\end{abstract}


achieved by general ward care alone. In all of these examples, the length of ICU stay was estimated to be relatively long, and thus be at least moderately costly in terms of expected ICU resource used. It must be stressed that these examples were constructed during and after the consensus meeting and are based on the experience of the clinical members of the consensus group. The triage thresholds set were based on a consensus of the members present, and are not intended to be prescriptive, but indicative of thresholds that the expert group considered to be at least reasonable in a unit with chronic resource limitations and the need to refuse referred patients on most days, because of insufficient available beds. During development of the examples, the severe burn criteria (as currently presented in Table 2) were considered to be too strict in one tertiary academic unit with relatively more resources, but considered too liberal to represent what was currently practised in a regional ICU situated in a smaller city with more limited resources. In addition, the greater expertise and clinical support in the tertiary unit made the odds of survival greater. These differences are expected, and provide an example of how local policy should adjust criteria to meet appropriate local resource conditions. For this reason, it is appropriate and important that one or more of the criteria in the examples provided here are adjusted, removed and/or others added to properly guide local practice. These adjustments, once incorporated into the local triage policy, should be reviewed and updated from time to time, as resource conditions may change.

For these examples, long-term benefit may reasonably be expected to fail to provide at least a $20-30 \%$ incremental chance of survival for a severely ill patient at $3-6$ months to qualify for the triage threshold. This assumes no more than a 5\% chance of survival if the patient was left at their original level of care (usually a general ward). This 20 - 30\% threshold may be insufficiently stringent for units in severely under-resourced regions, and thresholds may require greater stringency in such units. Conversely, in the privately funded sector, generally greater resource availability means triage thresholds may be considerably less stringent, i.e. patients with similar, or even lower, survival benefit accepted for admission.

In the South African setting, it is recommended that incremental benefit should be largely determined by the likely effect of ICU admission on mortality; however, in some circumstances, when expected quality of life is likely to be severely impaired, even with ICU care, functional outcomes and quality of life should also be considered in decision-making. Examples of such circumstances are provided in Table 3.

As previously stated, to promote consistency in decision-making, and transparency for all stakeholders, individual units are encouraged to develop and document their own thresholds for triage decisionmaking as far as possible. It would be ideal for thresholds to remain relatively constant over time, but it must be acknowledged that thresholds may change from time to time, depending on periodic changes in resources available and pressure for ICU beds. For example, temporary closure of ICU beds will force a greater number of refusals, and a greater benefit may be required by individual patients to meet admission thresholds. Similar adjustments to the admission threshold may be justified during infectious disease

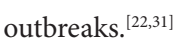

Nevertheless, on a day-to-day basis, a consistent triage threshold based on the above principles is desirable. Consistency of thresholds and decision-making over time allows doctors working within the ICU and referring teams to share appropriate expectations, and promotes fairness for all patients requiring ICU care. This approach specifically does not support the view that the sickest patient should necessarily receive priority, or the view that patients should be admitted only on a first-come, first-served basis. Only in the unusual circumstance when two or more patients under consideration for triage may have an equal triage priority, is admission on a first-referred, first-admitted basis recommended.

\subsection{Elective admissions}

Postoperative care in ICU is often required for patients who are not currently acutely ill, but require elective surgery and/or have major procedures and/or significant pre-morbid conditions. While delays caused by cancellation may be justified, such surgery can ultimately be considered lifesaving, and of benefit to society at large. Therefore, considerations should be made by individual units to reasonably accommodate elective surgery. These considerations should recognise that ICU length of stay is generally short, and consequently resource use by postoperative cases is relatively small. ${ }^{[32-34]}$ Nevertheless, it must be explicitly acknowledged that, from time to time, resource constraints may result in cancellation/delay of elective cases.

\section{Implementation and documentation}

\subsection{Implementation and responsibility for decision- making}

Each ICU in SA that is required to triage patients should have a triage policy. Some barriers to effective implementation of a triage policy can be anticipated; these include lack of acceptance of the triage policy by administrators or healthcare workers, as well as implementation and maintenance costs. Because the additional infrastructure and clinical manpower required to maintain a triage system is small, this should not be a major barrier to implementation. Developing and maintaining a well-accepted policy is more challenging and time consuming. The present guideline is intended to provide a framework on which local triage policy may be modelled. All local policies should be developed and endorsed by a high-level hospital triage committee (or equivalent high-level hospital management committee), chaired by the director of ICU or their nominated representative. Implementation of the local triage policy should also follow a defined administrative process (Table 4) that includes communication and consultation with stakeholders (e.g. ICU doctors, ICU nurses, hospital administrators, potential referring medical teams, and patient advocates). Potential referring teams that should be involved will differ according to the individual unit but would usually include family and emergency medicine, neurosurgery, trauma and general surgery, orthopaedics, obstetrics and gynaecology, general medicine and oncology. The product should demonstrate a rational process that all stakeholders can accept as relevant to fair resource rationing, be fully transparent, and openly published. Lastly, procedures for revising decisions in the light of reasonable challenges to them should be put in place. ${ }^{[35,36]}$ All these aspects should be built into the guideline development process, as was recently described in a South African paediatric ICU setting. ${ }^{[37]}$ 
Although clinical input from other medical professionals to establish prognosis is valuable, in daily operations the ICU team representative should be ultimately responsible for making decisions on admission and discharge according to this guidance and individual hospital policies. This representative should be a senior ICU doctor, or supervised by a senior ICU doctor. ${ }^{[12,15]}$ In cases of conflict with referring physicians, or the patient, or their surrogate, the ICU director's decision should be final. ${ }^{[12]}$ It is recommended that the ICU doctor responsible for triage should be the ultimate decision maker, as they are generally the least conflicted by previous association with individual patients, and have the best understanding of expected ICU outcomes, current ICU resource limitations and the resource implications of potential admissions. If there is an irreconcilable disagreement between the ICU director and other clinical departments, the ICU management committee or relevant hospital management committee, including the ethics committee if appropriate, should be responsible for facilitating resolution.

\subsection{Monitoring and audit}

Triage decisions carry a heavy burden, and ICU refusal on the basis of triage is associated with excess mortality, even after adjustment for severity of illness and comorbidity. ${ }^{[1738,39]}$ It is therefore important that there should be formal monitoring of the consequences of triage decisions.

The guidelines should be reviewed on a regular basis by relevant hospital committees and revised as needed. Performance indicators such as compliance with the guidelines, triage and ICU refusal rates, average length of ICU stay, re-admission rate, and ICU outcomes should also be reviewed regularly, and improvement measures implemented when appropriate. A list of key audit metrics that should be recorded to assist the process of continuous quality improvement can be found in the accompanying consensus statement. ${ }^{[10]}$ Relevant feedback should be clearly communicated to the frontline ICU doctors, hospital administrators as well as relevant regional and national authorities when necessary.

\subsection{Documentation}

Triage decisions should always be documented in writing in the patient record. This should include the triage priority and clinical reasons for the decision. The decision should be conveyed to the referring doctor/s and, where appropriate, the patient or patient's surrogate. Transparency and good communication of the reasons for admission or refusal in individual cases is critical to improve all stakeholders' understanding of the triage process and potentially avoids conflict with other healthcare providers and patients or surrogates.

\section{6. 'Goals of care' discussion}

In a situation where a patient does not meet the triage threshold for admission, a patient's or surrogate's preference for admission must be overridden. This is necessary in order to maintain fairness, and thus triage decisions must be made without patient or surrogate consent. ${ }^{[6]}$ It is, nevertheless, good practice for the ICU doctor to discuss 'goals of care' with patients or their surrogates either at the time of ICU referral, or soon after admission to the ICU. ${ }^{[40-43]}$ An honest evaluation and communication to the patient and surrogate of likely prognosis, and the benefits as well as burdens of ICU care, forms an important part of a 'goal of care' discussion. Some patients, or surrogates, who have been offered ICU care, may elect to exercise their autonomy at the time of referral by declaring a preference to decline ICU admission if they perceive likely outcome benefits to be outweighed by expected burdens of intensive care and/or the subsequent rehabilitation process. This situation offers patients the ability to exercise their autonomy and make informed medical choices.

While it is desirable to have a discussion with relevant parties establishing a potential ICU patient's circumstances including functional capacity and quality of life prior to making a triage decision, as it is required to assist decision-making, it is recommended that a formal 'goals of care' discussion take place only after the triage decision is finalised and has been communicated to the referring healthcare team and patient or patient's surrogate. This is important to avoid the circumstance where a patient or surrogate may indicate a desire for admission to ICU when such an option has been denied by the need to triage.

\section{Special circumstances}

Some patients may be declared dead by formal brain testing. To facilitate the important role of organ donation and the benefits it brings to society, such admissions may be justified in order to ensure the optimal condition of organs for transplantation by facilitating 'extracranial support' for a limited period of time. ${ }^{[4]}$ Such ICU admissions are justified on the basis of substantial societal gain for relatively small use of resources.

In some hospitals, alternative facilities such as high-dependency units, or ward ventilation, may be available for patients requiring life support and/or monitoring. While recognising that such care is not optimal, or equivalent to ICU care, some outcome benefit may be achieved for selected individual patients. ${ }^{[45]}$ If no alternatives exist, patients should be offered the best lower level of care available.

Occasionally, patients referred to ICU may have no realistic prospect of deriving benefit from ICU care, and thus ICU admission may be considered 'futile' or 'non-beneficial. ${ }^{[12,13]} \mathrm{A}$ recent consensus conference suggested that the use of the term 'potentially inappropriate' be considered unless the treatment requested had no prospect of accomplishing its intended physiological goal, in which case the use of the term 'futile' could be considered appropriate. ${ }^{[46]}$ There is a lack of consensus and some controversy surrounding the use of quantitative definitions of non-beneficial interventions (e.g. an intervention that achieves its goal in less than 1 in 100 cases). ${ }^{[6,13,47]}$ The determination of non-beneficial care therefore remains one that should be made by a senior doctor, preferably by consensus with other treating or consulted doctors. Where ICU care is deemed 'non-beneficial' or 'potentially inappropriate' patients should not be admitted to the ICU. Examples of severely ill or injured patients who might reasonably be considered to fall into this category are provided in Table 5. ${ }^{[12,16]}$ Patients at the other end of the admission spectrum, usually less severely ill or injured, who would derive very little or no anticipated incremental benefit from ICU admission, because equivalent interventions are available in a non-ICU setting, should also be refused admission. Examples may include stable patients after uneventful general anaesthesia for minor limb surgery, or a healthy postpartum mother.

\section{Patient discharge from ICU}

Ensuring the best use of ICU resources for all patients requires that patients who no longer need intensive care are expeditiously 
discharged. The status of patients admitted to an ICU should be assessed continuously to identify patients who no longer require ICU care, and can be discharged. General principles to be considered when developing a local discharge guideline follow.

\subsection{Routine discharge}

Patients who no longer require intensive monitoring or treatment should be discharged immediately. ${ }^{[12,13]}$

The majority, ${ }^{[48-54]}$ but not all studies, ${ }^{[49,55]}$ have demonstrated that after-hours (night-time) discharge is associated with higher mortality and increased risk for re-admission, ${ }^{[48-54]}$ and after-hours discharge should be avoided unless the bed is immediately required for a new admission.

The care that the patient receives at the discharge destination must be sufficient to provide a safe standard of care appropriate to the patient's health needs. Therefore, most patients in SA will have to be assessed as stable enough to be suitable for discharge to general wards, whereas some may be reasonably discharged to highdependency units in a less stable condition if such facilities exist.

Discharge to high-dependency units as a step-down option is likely to be efficient in 'protecting' ICU beds for sicker patients who will benefit from ICU admission into freed beds.

\subsection{Expedited/early discharge of patients with a good outcome prognosis}

Patients who may require additional monitoring, but are not in immediate danger of deterioration without ICU care, may be discharged when a bed is urgently required for another patient with a comparatively higher priority of ICU care. This may be considered when risks to the discharged patient are predicted to be small, and the likely benefit of the patient admitted to the freed bed to be high. Whenever possible, these patients should be discharged to a highcare area.

\subsection{Expedited/early discharge of patients with a poor outcome prognosis}

Patients whose treatment has failed so that short-term prognosis is poor, or those with little likelihood of recovery and benefit from continued intensive treatment, may be discharged to the ward or other lower levels of care such as high-dependency units for palliative care and/or end-of-life care electively, or when a bed is urgently required for another patient with a comparatively higher priority for ICU care. It is expected that the discharged patient's prognosis is manifestly very poor, and that the likelihood of benefit to the patient queueing for the freed bed is high. It is recommended that ICUs and other hospital units collaborate with such end-of-life care management, and consider introducing or promoting existing palliative care systems and protocols to assist in the care of such patients.

\section{Limitations}

The complexity of decision-making and a lack of precise medical knowledge means that a certain amount of inaccuracy will always be present when triage decisions are made. It must be acknowledged that predictions of outcome (e.g. mortality, functional outcomes, and quality of life) and ICU length of stay will, in practice, be imprecise. While some scoring systems are able to accurately predict outcomes such as mortality and ICU length of stay in patient populations, a lack of calibration leads to an inability of models to sufficiently discriminate outcomes accurately in individual patients. ${ }^{[23]}$ In addition, triage decisions must be made within a short period of time, and it is usually not possible to gather all the data required to make scorebased predictions in the time frame necessary. Current evidence suggests that scoring systems and clinical calculators are not yet superior to clinical judgment in correctly predicting mortality for individual patients, especially early after presentation. ${ }^{[56]}$ The clinical prediction of mortality by individual doctors, especially when confident about a particular prediction, is relatively good, and rises even better when in concordance with the prediction of others. ${ }^{[57]}$ Nevertheless, prognostic scoring systems, when available, have been recommended to assist and inform a greater degree of quantitative decision-making. ${ }^{[6,13]}$

In addition to predicting outcome if admitted to the ICU, it is also necessary to predict outcome for critically ill referred patients should they remain in their current care environment, so that incremental benefit can be estimated. Such predictive data for patients outside the ICU are sparse and necessarily rely largely on clinical judgment.

Accurate predictive scores of quality of life after ICU admission for individual patients are similarly unavailable, and the expert group recommends that poor quality of life only be considered as an outcome measure when is likely to be demonstrably and substantially poor (Table 4).

Estimating resource use is also problematic and carries a high degree of uncertainty. Current predictive scores for estimating ICU length of stay (as a surrogate for predicted resource use) have similar problems with predictions for individual patients as for mortality predictions, ${ }^{[58]}$ and models are complex and cannot be readily calculated at the time of admission. ${ }^{[59-61]}$ Available studies suggest that experienced doctors are moderately good at correctly estimating ICU length of stay (LOS) ${ }^{[62]} \mathrm{A}$ recent study suggested that while doctors predicted LOS correctly in only about $50 \%$ of cases, they underestimated LOS only in a minority (about $18 \%$ ) of cases. ${ }^{[63]}$

Finally, while several of the consensus group responsible for generating the guideline were chosen for their clinical expertise and experience in triage and the practice of intensive care in resource-limited environments, and the guideline was developed after an extensive review of current literature, a limitation of the statement was the lack of additional external expert review during the development process.

\section{Conclusion}

The process of triage has complex ethical and moral dimensions, and requires clinical expertise to implement effectively and equitably. Triage decisions always require complex judgments and decisionmaking can be difficult, even for experienced clinicians. These guidelines and the associated decision-making framework are insufficient to solve all the difficulties encountered by ICU doctors and other stakeholders working in SA's challenging public health resource environment. They do, however, offer an expert consensus of how rationing can be justly applied, and suggest measures that should serve to improve the fairness and consistency with which these decisions are made. The guidelines should also serve as a starting point for further deliberation and/or improvement of triage practices in SA. They may also serve to stimulate research that will 
help illuminate the process of decision-making, and help define the magnitude of the resource limitations faced by ICU services in SA. Research is also required to measure relevant outcomes consequent on the practice of triage. The long-term goal is ultimately to allow best delivery of ICU services to those requiring them.

Endorsement. The Guideline is endorsed by the Critical Care Society of Southern Africa (CCSSA).

Author contributions. GMJ led the consensus process, developed and supervised the methodology, and chaired the face-to-face round-table meeting. Responsible for initial drafting of consensus key questions and supervised the Delphi process, including the drafting and grading of recommendations. Drafted the manuscripts, supervised revisions to the drafts, and approved the final manuscripts.

FP chose the participants, co-chaired the face-to-face round-table meeting, co-drafted the initial consensus key questions, took part in the Delphi process, led the literature review of a designated section, drafted and graded associated recommendations. Participated in revisions to the drafts, and approved the final manuscripts.

IJ chose the participants, participated in the Delphi process and faceto-face round-table meeting, led the literature review of a designated section, drafted and graded associated recommendations. Participated in revisions to the drafts, and approved the final manuscripts.

VKWL devised and performed literature searches, reviewed methodology, participated in revisions to the drafts, and approved the final manuscripts. $\mathrm{AL}$ developed and supervised the methodology, performed literature searches, participated in manuscript drafting and revisions to the drafts, and approved the final manuscripts.

DG, AA, SC, RW, EH, SM, ST, GR, CM, RM, BE, BL, KA participated in the Delphi process and face-to-face round-table meeting, led the literature review of a designated section, drafted and graded associated recommendations. Participated in revisions to the drafts, and approved the final manuscripts.

Conflicts of interest. GMJ: Steering committee member and international instructor of the Basic Assessment and Support in Intensive Care (BASIC) educational collaboration, that received unrestricted educational grants from Maquet, Hamilton Medical and Draeger. LRM: Immediate Vice President of the Critical Care Society of Southern Africa. DG, AA, SC, RW, VKWL, EH, AL, IJ, SM, ST, GAR, CM, BE, BL, KA, FP: The remaining authors have stated that they do not have any potential conflicts of interest. Funding. The authors would like to thank the CCSSA for supporting the cost of the venue for the face-to-face meeting and accommodation of the participants. The costs of air travel for national participants was supported by the CCSSA Congress, Sun City, 2017. The CCSSA is a nonprofit organisation dedicated to delivering appropriate, quality care to the critically ill. It was founded in 1970, and represents doctors, nurses and allied health practitioners working in the field of intensive care medicine. The CCSSA provides professional development; research; guidelines; protocols; accreditation; training; conferences and seminars to its members and possesses recognised expertise in the practice of intensive care. The Society has developed numerous administrative guidelines and clinical practice parameters for the intensive care practitioner. New guidelines and practice parameters are continually developed, and current ones are systematically reviewed and revised to promote professional conduct, appropriate delivery of care and ethical practice for all practitioners in Critical Care. The authors declare that the views or interests of the funding bodies have not influenced the final recommendations.
1. Marshall JC, Bosco L, Adhikari NK, et al. What is an intensive care unit? A report of the task force of the World Federation of Societies of Intensive and Critical Care Medicine. J Crit Care 2017;37:270-276. https://doi.org/10.1016/j.jcrc.2016.07.015

2. van Zyl-Smit R, Burch V, Willcox P. The need for appropriate critical care service provision at non-tertiary hospitals in South Africa. S Afr Med J 2007;97(4):268-272.

3. Bhagwanjee S, Scribante J. National audit of critical care resources in South Africa - unit and bed distribution. S Afr Med J 2007;97(12 Pt 3):1311-1314

4. Naidoo K, Singh J, Lalloo U. Critical analysis of ICU/HC beds in South Africa: 2008-2009. S Afr Med J 2013;103(10):751-753.

5. Skinner DL, De Vasconcellos K, Wise R, et al. Critical care admission of South African (SA) surgical patients: Results of the SA Surgical Outcomes Study. S Afr Med I 2017;107(5):411419. https://doi.org/10.7196/SAMJ.2017.v107i5.11455

6. Sprung CL, Danis M, Iapichino G, et al. Triage of intensive care patients: Identifying agreement and controversy. Intensive Care Med 2013;39(11):1916-1924. https://doi. org/10.1007/s00134-013-3033-6

7. Ramos JG, Perondi B, Dias RD, et al. Development of an algorithm to aid triage decisions for intensive care unit admission: A clinical vignette and retrospective cohort study. Crit Care 2016:20:81. https://doi.org/10.1186/s13054-016-1262-0

8. Farmer AP, Legare F, Turcot L, et al. Printed educational materials: Effects on professional practice and health care outcomes. Cochrane Database Syst Rev 2008(3):Cd004398. https:// doi.org/10.1002/14651858.CD004398.pub2

9. Kredo T, Bernhardsson S, Machingaidze S, et al. Guide to clinical practice guidelines: The current state of play. Int J Qual Health Care 2016;28(1):122-128. https://doi.org/10.1093/ intqhe/mzv115

10. Joynt GM, Gopalan PD, Argent A, et al. The Critical Care Society of Southern Africa Consensus Statement on ICU Triage and Rationing (ConICTri). S Afr Med J 2019;109(8):613629. https://doi.org/10.7196.SAMJ.v109i8.13947

11. Lumb P. The Durban declaration. J Crit Care 2013;28(6):887-889. https://doi.org/10.1016/j. jcrc.2013.10.001

12. Guidelines for intensive care unit admission, discharge, and triage. Task Force of the American College of Critical Care Medicine, Society of Critical Care Medicine. Crit Care Med 1999;27(3):633-638.

13. Nates JL, Nunnally M, Kleinpell R, et al. ICU admission, discharge, and triage guidelines: A framework to enhance clinical operations, development of institutional policies, and further research. Crit Care Med 2016;44(8):1553-1602. https://doi.org/10.1097/ ccm. 0000000000001856

14. Sprung CL, Geber D, Eidelman LA, et al. Evaluation of triage decisions for intensive care admission. Crit Care Med 1999;27(6):1073-1079.

15. Blanch L, Abillama FF, Amin P, et al. Triage decisions for ICU admission: Report from the Task Force of the World Federation of Societies of Intensive and Critical Care Medicine. J Crit Care 2016;36:301-305. https://doi.org/10.1016/j.jcrc.2016.06.014

16. Consensus statement on the triage of critically ill patients. Society of Critical Care Medicine Ethics Committee. JAMA 1994;271(15):1200-1203.

17. Joynt GM, Gomersall CD, Tan P, et al. Prospective evaluation of patients refused admission to an intensive care unit: triage, futility and outcome. Intensive Care Med 2001;27(9):1459-1465. https://doi.org/10.1007/s001340101041

18. Joynt GM, Gomersall CD. Making moral decisions when resources are limited - an approach to triage in ICU patients with respiratory failure. S Afr J Crit Care 2005;21(1):34-44.

19. Joynt GM, Gomersall $\mathrm{CD}$. What do "triage" and "informed consent" really mean in practice? Anaesth Intensive Care 2011;39(4):541-544.

20. Joynt GM, Gomersall C. Integrating elective workloads into an emergency setting in the intensive care unit. In: Flaatten H, Moreno RP, Putensen C, Rhodes A, eds. Organisation and Management of Intensive Care. Berlin: MedizinischWissenschaftlicheVerlagsgesellschaft, 2010:53-64.

21. Brouwers MC, Kho ME, Browman GP, et al. AGREE II: Advancing guideline development, reporting and evaluation in healthcare. CMAJ 2010;182(18):E839-E842. https://doi. org/10.1503/cmaj.090449

22. Cheung WK, Myburgh J, Seppelt IM, et al. A multicentre evaluation of two intensive care unit triage protocols for use in an influenza pandemic. Med J Aust 2012:197(3):178-181.

23. Gomersall CD, Joynt GM. What is the benefit in triage? Crit Care Med 2011:39(4):911-912. https://doi.org/10.1097/CCM.0b013e31820b7415

24. Guest T, Tantam G, Donlin N, et al. An observational cohort study of triage for critical care provision during pandemic influenza: 'Clipboard physicians' or 'evidenced based medicine'? Anaesthesia 2009;64(11):1199-1206. https://doi.org/10.1111/j.1365-2044.2009.06084.x

25. Khan Z, Hulme J, Sherwood N. An assessment of the validity of SOFA score based triage in H1N1 critically ill patients during an influenza pandemic. Anaesthesia 2009;64(12):12831288. https://doi.org/10.1111/j.1365-2044.2009.06135.x

26. Shahpori R, Stelfox HT, Doig CJ, Boiteau PJ, Zygun DA. Sequential organ failure assessment in H1N1 pandemic planning. Crit Care Med 2011;39(4):827-832. https://doi.org/10.1097/ CCM.0b013e318206d548

27. Higgins TL, Teres D, Copes WS, et al. Assessing contemporary intensive care unit outcome: An updated mortality probability admission model (MPM0-III). Crit Care Med 2007;35(3):827-835. https://doi.org/10.1097/01.Ccm.0000257337.63529.9f

28. Cowen ME, Czerwinski JL, Posa PJ, et al. Implementation of a mortality prediction rule for real-time decision making: feasibility and validity. J Hosp Med 2014;9(11):720-726. https:// doi.org/10.1002/jhm.2250

29. Christian MD, Hawryluck L, Wax RS, et al. Development of a triage protocol for critical care during an influenza pandemic. CMAJ 2006;175(11):1377-1381. https://doi.org/10.1503/ cmaj.060911

30. Christian MD, Joynt GM, Hick JL, et al. Chapter 7. Critical care triage. Intensive Care Med 2010;36(Suppl 1):S55-S64. https://doi.org/10.1007/s00134-010-1765-0

31. Christian MD, Fowler R, Muller MP, et al. Critical care resource allocation: Trying to PREEDICCT outcomes without a crystal ball. Crit Care 2013;17(1):107. https://doi. org/10.1186/cc11842

32. Lupei MI, Chipman JG, Beilman GJ, Oancea SC, Konia MR. The association between ASA status and other risk stratification models on postoperative intensive care unit outcomes. AnesthAnalg 2014;118(5):989-994. https://doi.org/10.1213/ane.0000000000000187

33. Joliat GR, Labgaa I, Petermann D, et al. Cost-benefit analysis of an enhanced recovery protocol for pancreaticoduodenectomy. Br J Surg 2015;102(13):1676-1683. https://doi. org/10.1002/bjs.9957 
34. Li M, Zhang J, Gan TJ, et al. Enhanced recovery after surgery pathway for patients undergoing cardiac surgery: A randomized clinical trial. Eur J Cardiothorac Surg 2018;54(3):491-497. cardiac surgery: A randomized clinicel
https://doi.org/10.1093/ejcts/ezy100

35. Daniels N, Sabin J. Limits to health care: Fair procedures, democratic deliberation, and the legitimacy problem for insurers. Philos Public Aff 1997;26(4):303-350.

36. Daniels N. Accountability for reasonableness. BMJ 2000;321(7272):1300-1301.

37. Argent AC, Ahrens J, Morrow BM, et al. Pediatric intensive care in South Africa: An account of making optimum use of limited resources at the Red Cross War Memorial Children's Hospital. Pediatr Crit Care Med 2014;15(1):7-14. https://doi.org/10.1097/pcc.0000000000000029

38. Simchen E, Sprung CL, Galai N, et al. Survival of critically ill patients hospitalized in and out of intensive care units under paucity of intensive care unit beds. Crit Care Med 2004;32(8):1654-1661.

39. Edbrooke DL, Minelli C, Mills GH, et al. Implications of ICU triage decisions on patient mortality: A cost-effectiveness analysis. Crit Care 2011;15(1):R56. https://doi.org/10.1186/ Cc10029

40. Bernacki RE, Block SD. Communication about serious illness care goals: A review and synthesis of best practices. JAMA Intern Med 2014;174(12):1994-2003. https://doi.org/10.1001/ jamainternmed.2014.5271

41. Joynt GM, Lipman J, Hartog C, et al. The Durban World Congress Ethics Round Table IV: Health care professional end-of-life decision making. J Crit Care 2015;30(2):224-230. https:// doi.org/10.1016/j.jcrc.2014.10.011

42. Brighton LJ, Bristowe K. Communication in palliative care: talking about the end of life before the end of life. Postgrad Med J 2016;92(1090):466-470. https://doi.org/10.1136/ postgradmedj-2015-133368

43. Thomas RL, Zubair MY, Hayes B, Ashby MA. Goals of care: A clinical framework for limitation of medical treatment. Med J Aust 2014;201(8):452-455.

44. Cooper DK, De Villiers JC, Smith LS, et al. Medical, legal and administrative aspects of cadaveric organ donation in the RSA. S Afr Med J 1982;62(25):933-938.

45. Tang WM, Tong CK, Yu WC, Tong KL, Buckley TA. Outcome of adult critically ill patients mechanically ventilated on general medical wards. Hong Kong Med J 2012;18(4):284-290.

46. Bosslet GT, Pope TM, Rubenfeld GD, et al. An official ATS/AACN/ACCP/ESICM/SCCM policy statement: responding to requests for potentially inappropriate treatments in intensive care units. Am J Respir Crit Care Med 2015:191(11):1318-1330. https//doiorg/10.1164/

47. Schneiderman LJ, Jecker NS, Jonsen AR. Medical futility: Its meaning and ethical implications. Ann Intern Med 1990;112(12):949-954.

48. Duke GJ, Green JV, Briedis JH. Night-shift discharge from intensive care unit increases the mortality-risk of ICU survivors. Anaesth Intensive Care 2004;32(5):697-701.

49. Hanane T, Keegan MT, Seferian EG, Gajic O, Afessa B. The association between nighttime transfer from the intensive care unit and patient outcome. Crit Care Med 2008:36(8):2232-2237. https://doi.org/10.1097/CCM.0b013e3181809ca9
50. Laupland KB, Shahpori R, Kirkpatrick AW, Stelfox HT. Hospital mortality among adults admitted to and discharged from intensive care on weekends and evenings. J Crit Care 2008:23(3):317-324. https://doi.org/10.1016/j.jcrc.2007.09.001

51. Laupland KB, Misset B, Souweine B, et al. Mortality associated with timing of admission to and discharge from ICU: A retrospective cohort study. BMC Health Serv Res 2011;11:321 https://doi.org/10.1186/1472-6963-11-321

52. Tobin AE, Santamaria JD. After-hours discharges from intensive care are associated with increased mortality. Med J Aust 2006;184(7):334-337.

53. Singh MY, Nayyar V, Clark PT, Kim C. Does after-hours discharge of ICU patients influence outcome? Crit Care Resusc 2010;12(3):156-161.

54. Ouanes I, Schwebel C, Francais A, et al. A model to predict short-term death or readmission after intensive care unit discharge. J Crit Care 2012;27(4):422.e421-429. https://doi. org/10.1016/j.jcrc.2011.08.003

55. Makris N, Dulhunty JM, Paratz JD, Bandeshe H, Gowardman JR. Unplanned early readmission to the intensive care unit: A case-control study of patient, intensive care and ward-related factors. Anaesth Intensive Care 2010;38(4):723-731.

56. Sinuff T, Adhikari NK, Cook DJ, et al. Mortality predictions in the intensive care unit: Comparing physicians with scoring systems. Crit Care Med 2006;34(3):878-885. https://doi. org/10.1097/01.Ccm.0000201881.58644.41

57. Detsky ME, Harhay MO, Bayard DF, et al. Discriminative accuracy of physician and nurse predictions for survival and functional outcomes 6 months after an ICU admission. JAMA predictions for survival and functional outcomes 6 months after

58. Woods AW, MacKirdy FN, Livingston BM, Norrie J, Howie JC. Evaluation of predicted and actual length of stay in 22 Scottish intensive care units using the APACHE III system. Acute physiology and chronic health evaluation. Anaesthesia 2000;55(11):1058-1065.

59. Zimmerman JE, Kramer AA, McNair DS, Malila FM, Shaffer VL. Intensive care unit length of stay: Benchmarking based on Acute Physiology and Chronic Health Evaluation (APACHE) IV. Crit Care Med 2006;34(10):2517-2529. https://doi.org/10.1097/01. Ccm.0000240233.01711.D9

60. Verburg IW, Atashi A, Eslami S, et al. Which models can I use to predict adult ICU length of stay? A systematic review. Crit Care Med 2017;45(2):e222-e231. https://doi.org/10.1097/ ccm.000000000000205

61. Kramer AA. Are ICU length of stay predictions worthwhile? Crit Care Med 2017;45(2):379380. https://doi.org/10.1097/ccm.0000000000002111

62. Gusmao Vicente F, Polito Lomar F, Melot C, Vincent JL. Can the experienced ICU physician predict ICU length of stay and outcome better than less experienced colleagues? Intensiv Care Med 2004;30(4):655-659. https://doi.org/10.1007/s00134-003-2139-7

63. Nassar AP, Jr., Caruso P. ICU physicians are unable to accurately predict length of stay at admission: A prospective study. Int J Qual Health Care 2016;28(1):99-103. https://doi. org/10.1093/intqhc/mzv112 


\section{Appendix: Author affiliations}

\begin{tabular}{|c|c|c|}
\hline Name & Affiliation & Biography \\
\hline Gavin Joynt & \begin{tabular}{|l|} 
Chairman and Professor, Department \\
of Anaesthesia and Intensive Care, The \\
Chinese University of Hong Kong \\
Honorary Chief of Service, Anaesthesia and \\
Intensive Care, Prince of Wales Hospital, \\
Hong Kong \\
Honorary Professor, School of Clinical \\
Medicine, Royal Brisbane Clinical Unit, The \\
University of Queensland
\end{tabular} & $\begin{array}{l}\text { Gavin Joynt trained in Anaesthesia and Intensive Care at Baragwanath } \\
\text { Hospital, South Africa. He is past Chairman of the Board of Intensive } \\
\text { Care of the Hong Kong College of Anaesthesiology, and council } \\
\text { member of the Hong Kong Society of Intensive Care Medicine } \\
\text { and the College of Intensive Care Medicine of Australia and New } \\
\text { Zealand. He has participated in a number of consensus meetings, and } \\
\text { published several research papers, editorials and book chapters related } \\
\text { to triage, epidemic triage and end-of-life care. Research and special } \\
\text { interests include ICU education, medical ethics, infection control, } \\
\text { and antibiotic pharmacokinetics. Researcher ID C-7606-2009, ORCid } \\
\text { https://orcid.org/0000-0002-5823-3435 }\end{array}$ \\
\hline Dean Gopalan & $\begin{array}{l}\text { Chief Specialist and Head of Department of } \\
\text { Anaesthesiology \& Critical Care, School of } \\
\text { Clinical Medicine, University of KwaZulu- } \\
\text { Natal, Durban, South Africa }\end{array}$ & $\begin{array}{l}\text { Dean Gopalan's qualifications are MB ChB (Natal), FCA (SA), } \\
\text { CritCare(SA). He is Head of Department and an anaesthesiologist/ } \\
\text { intensivist at King Edward VIII and Inkosi Albert Luthuli Hospitals, } \\
\text { Durban, South Africa. He is the current President of CCSSA, and is } \\
\text { President of Council of the College of Anaesthetists of CMSA. His } \\
\text { research interests include ethical decision-making in ICU, medical } \\
\text { education, and training in low-middle-income countries. }\end{array}$ \\
\hline Andrew Argent & $\begin{array}{l}\text { Professor, Head of Department Paediatrics } \\
\text { and Child Health, University of Cape Town } \\
\text { and Red Cross War Memorial Children's } \\
\text { Hospital, Cape Town, South Africa }\end{array}$ & $\begin{array}{l}\text { Andrew Argent has worked in the paediatric intensive care unit } \\
\text { (PICU) at the Red Cross War Memorial Children's Hospital since } \\
\text { 1988. He has been Director of the PICU since 1999, and has been } \\
\text { involved in the development of admission criteria in that unit. He is } \\
\text { a previous president of the Critical Care Society of Southern Africa, } \\
\text { and the World Federation of Paediatric Intensive and Critical Care } \\
\text { Societies. He has published several research papers in the domain } \\
\text { paediatric intensive care, including decision-making in resource } \\
\text { restricted environments. Currently he is involved in guideline } \\
\text { development in the area of paediatric transfusions and management } \\
\text { of sepsis. }\end{array}$ \\
\hline Sean Chetty & $\begin{array}{l}\text { Head, Clinical Department - } \\
\text { Anaesthesiology \& Critical Care, } \\
\text { Stellenbosch University and Tygerberg } \\
\text { Hospital, Cape Town, South Africa }\end{array}$ & $\begin{array}{l}\text { Sean Chetty is an anaesthetic intensivist working at the University } \\
\text { of Stellenbosch, in Cape Town, South Africa. His areas of research } \\
\text { interest include the management of pain and sedation in the critically } \\
\text { ill patient and acute pain management of the obstetric patient. Sean } \\
\text { Chetty has focused his attention on optimising critical care services } \\
\text { within resource-constrained environments, in order to ensure that } \\
\text { indigent patients can access the high level of care required. He has a } \\
\text { passion for expanding medical education and is regularly involved } \\
\text { in knowledge expansion initiatives for healthcare professionals in } \\
\text { South Africa and internationally. He is the previous past chairman } \\
\text { of the Egoli branch of the Critical Care Society of Southern Africa. } \\
\text { He is also an executive committee member of the SA Society of } \\
\text { Anaesthesiologists. }\end{array}$ \\
\hline Robert Wise & \begin{tabular}{|l|} 
Head, Clinical Unit Critical Care, Edendale \\
Hospital, Pietermaritzburg. Discipline of \\
Anaesthesiology and Critical Care, School of \\
Clinical Medicine, University of KwaZulu- \\
Natal, Durban, South Africa
\end{tabular} & $\begin{array}{l}\text { Rob Wise specialised in anaesthesiology at the University of KwaZulu- } \\
\text { Natal. He was awarded a Master's in Medicine and subspecialised in } \\
\text { Critical Care Medicine, and is currently completing a PhD. He has } \\
\text { served as president of the KwaZulu-Natal branch of the CCSSA, is } \\
\text { a member of the South African Peri-Operative Research Group, a } \\
\text { member of the CCSSA Research and Education Committee, and also } \\
\text { works on the Clinical Trials Working Group of the World Society of } \\
\text { Abdominal Compartment Syndrome. He has particular interests in } \\
\text { data collection/systems management and resource allocation, rational } \\
\text { blood use, and innovation in resource-poor areas. }\end{array}$ \\
\hline Veronica Ka Wai Lai & $\begin{array}{l}\text { Department of Anaesthesia and Intensive } \\
\text { Care, The Chinese University of Hong Kong }\end{array}$ & $\begin{array}{l}\text { Veronica Ka Wai Lai has completed a PhD at the Department of } \\
\text { Anaesthesia and Intensive Care, The Chinese University of Hong } \\
\text { Kong. Her undergraduate degree majored in psychology and she has } \\
\text { published papers in education and clinical medicine. Researcher ID } \\
\text { O-5672-2015. }\end{array}$ \\
\hline
\end{tabular}




\begin{tabular}{|c|c|c|}
\hline Eric Hodgson & $\begin{array}{l}\text { Chief Specialist, Department of Anaesthesia, } \\
\text { Critical Care and Pain Management at } \\
\text { Nelson R Mandela School of Medicine, } \\
\text { University of KwaZulu-Natal, Durban, } \\
\text { South Africa }\end{array}$ & $\begin{array}{l}\text { Eric Hodgson is a specialist anaesthesiologist with subspecialty } \\
\text { registration in critical care. He has worked as an intensivist in both the } \\
\text { state (Addington Hospital) and private sectors in eThekwini-Durban, } \\
\text { and has served on the Councils of the SA Society of Anaesthesiologists } \\
\text { and Critical Care Society of SA. Eric received the President's Award } \\
\text { from the CCSSA in } 2011 \text { and a Travelling Fellowship from SASA } \\
\text { in 2007. Eric has a special interest in the management of acute and } \\
\text { chronic pain, is a founder member of Pain SA and a contributing } \\
\text { author to the SA Acute and Cancer Pain guidelines. Eric is currently } \\
\text { the chief specialist anaesthesiologist and a pain physician at Inkosi } \\
\text { Albert Luthuli Central Hospital and an honorary clinical associate of } \\
\text { the Department of Anaesthesia, Critical Care and Pain Management } \\
\text { at Nelson R Mandela School of Medicine, University of KwaZulu- } \\
\text { Natal. He has published on ethical issues related to intensive care in } \\
\text { South Africa. }\end{array}$ \\
\hline Anna Lee & $\begin{array}{l}\text { Professor, Department of Anaesthesia and } \\
\text { Intensive Care, The Chinese University of } \\
\text { Hong Kong }\end{array}$ & $\begin{array}{l}\text { Anna Lee is an epidemiologist at the Department of Anaesthesia } \\
\text { and Intensive Care, The Chinese University of Hong Kong. She is } \\
\text { an editor for both the Cochrane Anaesthesia, and Emergency and } \\
\text { Critical Care Groups. She has published papers related to triage, end- } \\
\text { of-life, medical ethics, patient education and a diverse range of topics } \\
\text { examined in systematic reviews. Researcher ID B-2773-2009. ORCid } \\
\text { https://orcid.org/0000-0003-2864-0045 }\end{array}$ \\
\hline Ivan Joubert & $\begin{array}{l}\text { Director of Critical Care, Groote Schuur } \\
\text { Hospital, Cape Town, South Africa }\end{array}$ & $\begin{array}{l}\text { Ivan Joubert is currently President of the Critical Care Society of } \\
\text { Southern Africa, and Head of Critical Care, Groote Schuur Hospital } \\
\text { and the University of Cape Town. He is Chair of the Committee of } \\
\text { Critical Care of the Colleges of Medicine of South Africa, and Chair } \\
\text { of the Critical Care Forum for the Provincial Government of the } \\
\text { Western Cape. }\end{array}$ \\
\hline Sam Mokgokong & $\begin{array}{l}\text { Department of Neurosurgery, University of } \\
\text { Pretoria. Past President: Health Professions } \\
\text { Council of South Africa }\end{array}$ & $\begin{array}{l}\text { Sam Mokgokong is a practising neurosurgeon and an intensivist. He } \\
\text { recently retired as Head of the Department of Neurosurgery at the } \\
\text { University of Pretoria. He is a recently retired long-serving council } \\
\text { member of the CCSSA. }\end{array}$ \\
\hline Stephilia Tshukutsoane & $\begin{array}{l}\text { Critical Care Nurse, Chris Hani } \\
\text { Baragwanath Academic Hospital, Soweto, } \\
\text { Johannesburg, South Africa }\end{array}$ & $\begin{array}{l}\text { Critical care trained nurse working at Chris Hani Baragwanath } \\
\text { Academic Hospital. She is heavily involved in clinical trials research } \\
\text { within the unit, and has been study coordinator for numerous clinical } \\
\text { trials across all disciplines. }\end{array}$ \\
\hline Guy Richards & $\begin{array}{l}\text { Academic Head and Professor of Critical } \\
\text { Care, Faculty of Health Sciences, University } \\
\text { of the Witwatersrand, Johannesburg, South } \\
\text { Africa }\end{array}$ & $\begin{array}{l}\text { Guy Richards' qualifications are MB BCh, PhD, FCP(SA) and } \\
\text { FRCP. He is the Director of Critical Care at Charlotte Maxeke } \\
\text { Johannesburg Academic Hospital. He has delivered more than } 500 \\
\text { invited presentations at national and international congresses. He has } \\
\text { received numerous research awards, and was awarded the Mandela } \\
\text { Medal in Gold by the President for distinguished service related to } \\
\text { the passing of Nelson Mandela in } 2014 \text {. He has authored } 11 \text { book } \\
\text { chapters and } 156 \text { peer-reviewed indexed scientific papers. His RG } \\
\text { score on ResearchGate is } 40.91 \text { and his research has been cited } 2309 \\
\text { times. His ' } h \text { index' is } 27 \text {. He is a reviewer for many critical care and } \\
\text { pulmonology journals. }\end{array}$ \\
\hline Colin Menezes & $\begin{array}{l}\text { Academic Head and Associate Professor, } \\
\text { Department of Internal Medicine, Faculty } \\
\text { of Health Sciences, University of the } \\
\text { Witwatersrand, Johannesburg, South Africa }\end{array}$ & $\begin{array}{l}\text { Colin Menezes is an Associate Professor and Academic Head } \\
\text { of the Department of Internal Medicine at the University of the } \\
\text { Witwatersrand. He is also the Clinical Head of the Division of } \\
\text { Infectious Diseases and a senior specialist in a General Internal } \\
\text { Medicine Unit, Chris Hani Baragwanath Academic Hospital, in } \\
\text { Soweto. In addition to his research interests in infectious diseases, he } \\
\text { also has an interest in health law and medical ethics - he is the chair of } \\
\text { his hospital clinical review committee, and assists his local provincial } \\
\text { department with medico-legal cases. ORCid https://orcid.org/0000- } \\
0003-3838-5359 \text {. }\end{array}$ \\
\hline
\end{tabular}




\begin{tabular}{|c|c|c|}
\hline Lufuno Rudo Mathivha & $\begin{array}{l}\text { Adjunct Professor in Critical Care, } \\
\text { Department of Critical Care Medicine, } \\
\text { University of the Witwatersrand. Medical } \\
\text { Director of Intensive Care, Chris Hani } \\
\text { Baragwanath Academic Hospital, Soweto, } \\
\text { Johannesburg, South Africa }\end{array}$ & $\begin{array}{l}\text { L R Mathivha is the first black South African woman to study } \\
\text { critical care. She graduated from the University of Natal (South } \\
\text { Africa), completed a paediatric residency at Chris Hani Baragwanath } \\
\text { Academic Hospital before embarking to North Carolina USA. At } \\
\text { Duke University, she completed a fellowship in Paediatric Critical } \\
\text { Care. She is Director of Critical Care Medicine at Chris Hani } \\
\text { Baragwanath Academic Hospital; Vice President of the Society of } \\
\text { Critical Care of Southern Africa; Past Chairperson of the South } \\
\text { African Medical Association's Committee of Education, Science } \\
\text { and Technology; Member of the Ministerial Committees of Health } \\
\text { Technology Management and Revitalization of Emergency Medical } \\
\text { Services. She runs a combined adult and paediatric critical care } \\
\text { fellowship programme. }\end{array}$ \\
\hline Bronwen Espen & $\begin{array}{l}\text { Clinical Facilitator, Centre for Health } \\
\text { Professions Education, Stellenbosch } \\
\text { University, Cape Town, South Africa }\end{array}$ & $\begin{array}{l}\text { Bronwen Espen is a registered critical care nurse and an experienced } \\
\text { educator with an interest in clinical simulation, particularly focusing } \\
\text { on communication skills and teamwork. She is a council member of } \\
\text { CCSSA. }\end{array}$ \\
\hline Brian Levy & $\begin{array}{l}\text { Anaesthesiologist and critical care specialist, } \\
\text { private practice }\end{array}$ & $\begin{array}{l}\text { Brian Levy is an anaesthetist intensivist in private practice. He is a } \\
\text { co-founder of Nesibopho Healthcare, a institution that promotes } \\
\text { expert consensus and evidence-based intensive care practice. He is } \\
\text { currently also treasurer and private practice portfolio head of the } \\
\text { CCSSA. }\end{array}$ \\
\hline Kwanele Asante & $\begin{array}{l}\text { Lawyer, bioethicist, African cancer equity } \\
\text { activist }\end{array}$ & $\begin{array}{l}\text { Kwanele Asante is the Former Chairperson of the Ministerial Advisory } \\
\text { Committee on Cancer Prevention and Control in South Africa. She } \\
\text { taught Health Law at the Steve Biko Centre for Bioethics, at the } \\
\text { University of the Witwatersrand. Asante has received several awards } \\
\text { for her African cancer equity activism, including the Harvard Global } \\
\text { Health Catalyst - } 2016 \text { African Ambassador Award. She serves on the } \\
2019 \text { Global Advisory Committee of the NCD Alliance Geneva and } \\
\text { is a member of the Lancet High Quality Health Systems Commission } \\
\text { People's Voice Advisory Board, USA. }\end{array}$ \\
\hline Fathima Paruk & $\begin{array}{l}\text { Clinical and Academic Head of Department } \\
\text { and Associate Professor: Department of } \\
\text { Critical Care, Steve Biko Academic Hospital } \\
\text { and Kalafong Hospital, Faculty of Health } \\
\text { Sciences, University of Pretoria, South } \\
\text { Africa }\end{array}$ & $\begin{array}{l}\text { Fathima Paruk previously held the position of Director of the } \\
\text { Cardiothoracic ICU at Charlotte Maxeke Johannesburg Academic } \\
\text { Hospital, University of the Witwatersrand. Her current positions } \\
\text { include being a member of the University of the Witwatersrand } \\
\text { Human Research Ethics Committee, serving on the EXCO of the } \\
\text { Critical Care Society of Southern Africa (President-Elect) and the } \\
\text { Medical and Dental Board of the Health Professions Council of } \\
\text { South Africa. She currently chairs the Second Medical Committee of } \\
\text { Inquiry for the HPCSA and is a member of the Executive Committee } \\
\text { of the HPCSA, Medical and Dental Board. She has served on } \\
\text { several ministerially appointed committees including until recently } \\
\text { the National Health Research Committee as well as the National } \\
\text { Committee for Confidential Enquiries into Maternal Deaths in South } \\
\text { Africa. Critical care ethics constitutes one of her many research } \\
\text { interests. }\end{array}$ \\
\hline
\end{tabular}

